DOI: $10.12957 /$ concinnitas.2019.44869

\title{
Superfícies/feminilidades: 0 imperceptível como estratégia sobre o olhar
}

Amanda Brum de Moraes Ponce Devulsky ${ }^{1}$

Resumo: 0 artigo a seguir percorre o trabalho de diferentes autores para desenvolver uma reflexão que visa propor um território para um modo de olhar, praticar e existir em experiências estéticas que se dão na relação entre superfícies técnicas e conceitos políticos de feminilidade.

Palavras-chave: Feminilidades. Imagem técnica. Estéticas. Processos artísticos contemporâneos.

\section{Surfaces/femininities: The imperceptible as a strategy regarding seeing}

Abstract: The following article wanders between the work of different authors to develop a reflection that proposes a territory for a way of seeing, practicing and existing in aesthetic experiences that occur at the intersection of technical surfaces and political concepts of femininity.

Keywords: Femininities. Technical image. Aesthetics. Contemporary artistic processes.

\footnotetext{
1 Mestre em Arte e Cultura Contemporânea pelo Programa de Pós-Graduação em Artes da Universidade do Estado do Rio de Janeiro na linha de Processos Artísticos Contemporâneos. Bacharel em Audiovisual pela Universidade de Brasília. Realiza pesquisa teórico-prática ao redor da imagem técnica transitando entre cinema, fotografia e videoarte. É também realizadora dos trabalhos Tente não existir (21ํㅜ Festival Luso Brasileiro de Cinema), Fantasma cidade fantasma (Cinélatino $30^{\circ}$ Rencontres de Toulouse), A outra caixa (Mostra Itinerante de Videoarte Feminista Bienal Miradas de Mujeres), entre outros, além de curadora do Cine Cleo e coeditora do Verberenas.
} 
They judge me like a picture book By the colours like they forgot to read ${ }^{2}$ - Lana Del Rey

0 presente texto parte de uma simples motivação: estar nos territórios das políticas do imperceptível, olhar para feminilidade enquanto conceito político, pensar as possibilidades de manifestação dessas sensibilidades na superfície técnica. Se a intenção é questionar que poéticas podem surgir desse lugar, o passo exposto aqui é o primeiro, ou seja, aquele de definir o lugar.

Explico a definição desse recorte conceitual em que tal mapeamento se dá: ele surge em um ponto que pode ser determinado como a intersecção de três linhas. A primeira linha é o conceito de imagem técnica como definida pelo filósofo Vilém Flusser (1984), que é útil para pensar toda e qualquer imagem que é gerada a partir de um aparelho, proporcionando um pensamento que não esteja excessivamente voltado para as diferenças e separações ontológicas entre as imagens da fotografia, cinema, vídeo, novas mídias, arte digital e afins. A ideia não é rejeitar ou ignorar especificidades entre os citados, mas evitar sua sobrevalorização. Pensar sua convergência parece mais prolífico: o que têm em comum, como funcionam, como as experienciamos, quais são seus potenciais.

A segunda linha que compõe essa intersecção é composta pela ideia de dimensão estética, junto à terceira linha, que trata da dimensão política expressa aqui pelo conceito de feminilidade. A proposta não é a de uma estetização da política ou uma politização da estética, mas a de enxergar o local desse encontro. Olho para a feminilidade enquanto conceito não essencialista, ou seja, para as associações simbólicas, ficções e experiências que se relacionam ao que foi descrito como

\footnotetext{
${ }^{2}$ Em português: "Me julgam como um livro de ilustrações / Pelas cores, como se esquecessem de ler".
} 
feminino, acompanhada da premissa de que não existe essência ou natureza que justifique por si só tais desdobramentos histórico-sociais.

No lugar em que a imagem técnica, manifestações estéticas e a feminilidade enquanto conceito político se encontram, podemos pensar em possíveis poéticas da atualidade. Dando um zoom nesse ponto de intersecção, seria possível encontrar uma outra rede, composta por construções de artistas, processos artísticos e recepções contextuais desses trabalhos. Não foco em tais pontos no presente texto, embora tal reflexão tenha partido também de uma relação com meus próprios processos e artistas/processos/obras que acompanho ao meu redor. Aqui, olho de maneira mais distante para a intersecção conceitual que se estabelece nesse local para esboçar a prática de um pensamento sobre a superfície e a feminilidade.

Primeiro, contextualizo ao apresentar o imperceptível e o dispensável da maneira que têm se mostrado tão entrelaçados às feminilidades. É quando falo dos pontos cegos. Em seguida, organizo um território. Coloco, então, três questões fundamentais: a feminilidade enquanto vazio, superfície e paródia; suas contribuições para um entendimento do que é comum; a resistência ao "inteiro", "certo" e "profundo" enquanto valoração e identidade. São indicativos de como quero desenvolver uma poética: levemente, por alto, pelo olhar, pela superfície, pelo contato, pela sensação e no momento presente. Sem fetiches de penetrar, aprofundar, dissecar em destruição - o que também não significa de forma alguma que será um olhar leviano; esta é precisamente a questão, a superfície como valor.

\section{Ponto cego}

"Sangue é vida", diz a adolescente Bia para seu namorado religioso no longametragem Mate-me por favor (2016), de Anita Rocha da Silveira. O filme, uma espécie de pesadelo pop de classe média alta em uma cidade vazia na qual não existem adultos, trata de uma onda de assassinatos e estupros de garotas adolescentes de um mesmo bairro e se detém na relação desses acontecimentos com a jovem protagonista e suas três amigas. 
Calcado em linguagem de artificialidade e, por vezes, de precariedade relativa a imagens digitais que circulam - selfies de poucos megapixels publicadas em redes sociais -, o filme com frequência parece pausar e permitir que as personagens nos olhem de volta. Uma parcela considerável do filme se configura de maneira a estabelecer essa sensação, como as coreografias organizadas de maneira frontal em relação à câmera, ou a ocasião do uso de enquadramento centralizado típico de dispositivos atuais como webcams ou as câmeras invertidas dos smartphones. 0 que é esteticamente construindo ali é visualmente agradável, plástico, “bonito”, mas, de certa forma, frívolo por parecer desejar seduzir.

A recepção do filme foi acompanhada de forma marcante por um tipo de crítica que repetia impressões parecidas: "perdido em seu exibicionismo formal",3 "a direção estilizada não é capaz de esconder o vazio no âmago do filme", 4 "esvaziado de um conceito mais significativo, o que resta é a forma" 5 e afins - ou seja, só aparência, sem conteúdo. Discurso que se confunde com o histórica e não raramente feito sobre mulheres: vazio; artificial; distante; perigoso; sedutor. Enquanto isso, no filme, as protagonistas olhavam para esses mesmos espectadores através da câmera. Depois olhavam obsessivamente nas redes sociais as fotos das garotas mortas.

"A cada morte anunciada, as meninas se imaginam morrendo. A cada morte no terreno baldio, vazio entre os prédios em uma cidade rarefeita, elas morriam um pouco. 'Vocês não podem ficar andando assim sozinhas'”6, escrevi sob o pseudônimo Karine no site colaborativo Verberenas alguns dias após ter assistido ao filme. Refletia então sobre a curiosa resposta crítica a um trabalho que trata justamente da experiência de existir sob o olhar masculino, o olhar externo que passa a viver

\footnotetext{
3 Trecho da crítica de Rodrigo Fonseca sobre o filme Mate-me por favor para o site Omelete, disponível em: <https://omelete.uol.com.br/filmes/criticas/mate-me-por-favor/?key=101017>; acessado em 14/06/2017.

${ }^{4}$ Trecho da crítica de Kevin Jagernauth para o site The Playlist, disponível em: $<\mathrm{http} / /$ theplaylist.net/anita-rocha-da-silveiras-kill-please-enigmatic-unsatisfying-lookadolescence-sex-death-afi-fest-review-20161114/>; acessado em 14/06/2017.

5 Trecho da crítica de Pedro Henrique Ferreira para a Revista Cinética, disponível em: $<$ http://revistacinetica.com.br/home/mate-me-por-favor-de-anita-rocha-da-silveira-brasil2015/>; acessado em 14/06/2017.

${ }^{6}$ Disponível em: <https://verberenas.com/2016/09/19/mate-me-por-favor/>; acessado em 14/06/2017.
} 
em nós, nos becos escuros, nos espaços públicos, nos relacionamentos íntimos, dentro de casa. Ou, como observou o crítico de arte John Berger (1972, p. 46), "Uma mulher deve vigiar continuamente a si mesma. Ela é continuamente acompanhada de modo quase permanente pela imagem que faz de si mesma”. Inconscientemente, as resenhas negativas da crítica masculina evidenciavam o que passei a denominar pontos cegos: os fatores que consistentemente tornavam a experiência do filme relevante para certa audiência e eram imperceptíveis para outra parcela de espectadores.

Historicamente, no que constituiu a epistemologia ocidental masculinista, o feminino foi repetidamente associado a algo natural, celestial e incorpóreo, a uma não verdade, ao não homem (= não humano), à magia, à distância que se deve manter da sedução, a um espaço negativo. Enquanto ao homem ocidental era dada a possibilidade de ser um sujeito no mundo e alcançar a conexão transcendental por meio de seu espírito ou racionalidade, à mulher era oferecido o destino supostamente natural de sacrifício, doação e o que foi chamado de amor - elementos que desmanchavam qualquer possibilidade de constituição de si. A mulher poderia ser tudo, menos uma pessoa. Tudo, menos sua própria realidade material. Ou então, apenas sua própria realidade material, tal qual percebida por eles:

Mulheres, ele sempre disse / são acorrentadas à terra / e embaraçadas demais / em todos os seus ciclos e fluxos confusos. E, no entanto, na outra mão invisível, mulheres são artificiais demais para homens: questão de charme, ilusão, truque. Até suas fundações são cosméticas: ela, em si, é inventada. (...) (PLANT, 2000, p. 37)

O caráter místico, ficcional e constitutivo desse emaranhado de noções acerca do feminino foi descrito por mulheres ao longo dos tempos e em especial no último século. Como a escritora Andrea Dworkin registrou, parafraseando Simone de Beauvoir:

A mulher não é nascida, é construída. Nessa construção, sua humanidade é destruída. Ela se torna símbolo disto, símbolo daquilo: mãe da Terra, puta do universo; mas ela não se torna nunca ela mesma, pois é proibido que ela o faça. (1979, p. 127) 
A teoria feminista e os estudos de gênero ao longo de seu desenvolvimento fizeram o favor de possibilitar a separação conceitual entre essa ideia mágica do que seria uma verdadeira mulher e a existência factual de pessoas de constituições sexuais femininas (e o fizeram não sem encontrar seus próprios obstáculos e dilemas). No cerne dessa separação original pode-se identificar conceitos de feminilidades, a partir de uma abordagem não essencialista.

Escrevi e publiquei inicialmente sobre Mate-me por favor, aquele texto simples e em primeira pessoa, a partir dessa perspectiva que se apoiava em minha própria prática artística e pesquisa acadêmica. Se o texto teve uma repercussão positiva que me surpreendeu, isso talvez possa ser atribuído também ao fato de que as vozes que publicavam sobre cinema brasileiro naquele momento apresentavam um perfil identitário um tanto restrito (uma realidade que se alterou de maneira significativa desde então). Eu não tinha um interesse especial em publicar esses textos críticos online - o que me havia motivado a divulgar aquele era exatamente a percepção crescente de uma falta nesse lado da perspectiva e de um problema não nomeado. A impressão era a de que não só historicamente, mas ainda hoje, ano após ano, trabalhos de artistas mulheres no campo que perpassa cinema, vídeo e fotografia sofriam devido a um problema de percepção.

As formas mais sutis e experimentais de tratar de questões da alteridade feminina, formas que se entrelaçam com uma poética da obra, por vezes não seriam vistas ou apreendidas por parte da crítica ou espectadores. Mais do que isso, com frequência uma obra feita por uma mulher precisaria ser escancaradamente política para que os guardiões da valoração estética notassem como a questão influenciava a percepção do trabalho. Ou então, uma situação ainda mais duvidosa: na tentativa de abordar essa questão, haveria a menção a um "olhar feminino", tratando a questão como consequência natural do sexo/gênero da artista, sem mais elaborações. Esses pontos cegos atuariam nessa rede de circulação das obras de forma a prejudicar até mesmo o próprio desenvolvimento artístico de mulheres que atravessam essa questão, pelo fato de elas estarem também cientes da expectativa de uma literalidade - um ciclo vicioso da invisibilidade que requereria estratégias políticas 
e estéticas para ser quebrado.

O que pretendo pensar aqui está dentro dessa relação estético-política. Volto-me para as alteridades referentes às experiências e ficções do feminino para tratar de feminilidades partindo de comportamentos/aparências/essências que uma "verdadeira mulher" deveria ter na sociedade ocidental e os seus desdobramentos. Se a feminilidade enquanto conceito é, de acordo com as teorias feministas e os estudos de gênero, desanexada de um índice sexual, qualquer pessoa, de qualquer gênero, pode empenhar-se em poéticas do feminino. A partir dessas teorias é possível entender esse conceito como uma sensibilidade, um modo de ser: uma imposição, mas também uma estratégia de sobrevivência; um papel a ser performado, mas também uma espécie de cultura construída a partir da experiência vivida historicamente por mulheres em um contexto de poderes assimétricos e hierárquicos.

Seguindo esse raciocínio, é evidente que existem diversos exemplos de obras que apresentam certa sensibilidade relacionada ao feminino e cujos autores não são designados mulheres. Elas existem; não são o foco aqui. Da mesma forma, não estou tratando exatamente de trabalhos que tenham conteúdo feminista ou que foquem em levantar questões sobre ser mulher. 0 ponto aqui é muito mais uma forma de olhar e uma forma de existir esteticamente que se mostra política, o que não infere a presença de um tema central necessária e diretamente sexual ou de gênero. Mais do que isso, não considero minha escolha de análise algo que olha para o que seria "ser uma mulher", mas para aspectos específicos (feminilidades) que são parte do que delineou a narrativa da ideia, certamente problemática, de mulher na sociedade ocidental.

Tudo o que é voltado para o feminino sofre certa resistência hegemônica. 0 feminino quando é expressado por sujeitos homens não é uma exceção, mas é cada vez menos visto hoje no universo contra-hegemônico como indesejado e mais como interessante e subversivo, felizmente. No entanto, o nó que me interessa aqui acontece quando essas sensibilidades femininas expressas por artistas mulheres 
seguem sendo vistas frequentemente tanto nas perspectivas hegemônicas quanto nas contra-hegemônicas como algo de reflexo impensado ou ato natural inevitável.

Bem antes de Mate-me por favor, a escritora e crítica de arte Chris Kraus (1997; 1998) pensou em questões relacionadas no caso da artista Hannah Wilke. Em sua novela epistolar I love Dick e em seu ensaio Private parts, public women, Kraus oferece uma defesa das complexas leituras, feitas por outras mulheres e ela mesma, da obra de Wilke, em oposição a leituras de homens que a apresentavam como narcisista ou sem teoria. Em um dos exemplos, Kraus (1997, p. 212-213) aponta a resenha escrita por James Collins publicada na revista Artforum por ocasião da exposição do vídeo Gestures, de Hannah Wilke, no qual ela própria figura: “Toda vez que vejo o trabalho dela, eu penso em buceta. (...) A posição de Wilke no mundo da arte é um estranho paradoxo entre sua própria beleza física e a seriedade de sua arte". 0 fato de os trabalhos de Wilke trazerem implicações formais em relação a sexualidade e ao corpo feminino pode ser usado pelos desatentos para justificar uma fala como essa. 0 que parece evidente, entretanto, é que seria ingênuo pensar que a questão do nó na recepção das estéticas relacionadas à feminilidade não está conectada ao problema histórico de autoria e identidade de mulheres.

Em um ensaio, a poeta e pesquisadora Abena Busia (1993) se relaciona às falas do filósofo Homi K. Bhabha sobre identidade e nos oferece algumas compreensões de linguagem que podem auxiliar o pensamento a respeito da experiência estética. A autora escreve que nenhum sujeito colonial, especialmente sendo mulher, pode realmente falar sem saber que a narrativa do mundo constituiu uma antítese às histórias dos sujeitos mulheres. Em um trecho de seu texto, que pode ser considerado central na presente pesquisa, Busia afirma que "um dos dilemas que enfrentamos é que, na linguagem do colonial, precisamos negociar visões de nós mesmas em línguas que inscrevem nossas próprias invisibilidades" (p. 207).

As colocações de Busia (1993) remetem também a conceituações sobre o problema da tradução, dos processos de trocas culturais e mediações, que sempre deixam algo não traduzido, opaco, faltante, ausente (ANJOS, 2005; MAHARAJ, 2001). Minha proposição é no sentido de me apropriar desse pensamento visando observar uma 
dinâmica relacionada. Nesse caso, tradução pensada não como negociação entre culturas de regiões globais, mas entre pessoas num mesmo contexto local, separadas pelas noções de sexo e suas materializações, que tomam corpo em densas experiências de hierarquias de gênero. Retornando a Abena Busia, fato é que da mesma forma que não se pode falar sem ter em mente tal antítese, não se pode olhar ou mesmo sentir sem sua noção. A experiência estética está a ela entrelaçada.

A sugestão que faço é que se resista a presumir o problema como meramente temático ou identitário, o que não significa dizer que não existem importantes raízes relacionadas a problemas de identidade e diferença na questão. Defendo, porém, que é a imbricação entre as experiências estéticas e políticas dessa ficção que toma formas bem concretas na realidade social e íntima. As poéticas permanecem ali em uma súplica pelo encontro, por serem de alguma forma vistas - antes mesmo de se saberem, antes de se tornarem. E durante, e depois. 0 risco dos vieses estético-políticos: é no momento em que se agarra ao que é singular à experiência que se corre o risco de não ser visto. 0 nó do ponto cego é perigoso porque ele vai aonde importa. A inércia na troca de olhares não é um acaso, é sintoma da dominação política, e não há solução simples a ser colocada.

Pensando no lugar que é reservado às poéticas relacionadas a noção de feminilidade, quais efeitos pode gerar a concentração deliberada nessas zonas opacas? Avaliar a possibilidade de tomar a falta de percepção como estratégia exige mapear onde ela reside.

\section{Vazio}

Quando Vilém Flusser (1984) se concentra em delinear uma proposta de filosofia da fotografia, apresenta também boa defesa de um pensamento estético fotográfico. Concordo com fotógrafo e pesquisador Osmar Gonçalves (2013) quando diz que Flusser parte com frequência de questões ontológicas - do que seria a imagem tradicional; do que seria a imagem técnica; do que seriam os gestos criadores da cultura e de que forma eles se diferem nessas duas práticas, objetos, experiências - 
e que as ferramentas com as quais Flusser avança nessas questões são, no entanto, marcadas por um olhar fenomenológico. Para Flusser, a significância das imagens, de toda imagem, se encontra em sua superfície. A diferença entre a imagem tradicional e a imagem técnica é que a imagem técnica exige um grau maior de abstração; ela não é fruto apenas de um gesto abstraidor, a mão do pintor que cria o quadro. Ela é fruto da história da cultura que gera o texto, que então gera o aparato, que então gera a imagem em um clique. A tal história da cultura, diz Flusser (2008), não é um progresso; é um dar passos para trás a fim de se ver melhor; uma dança em torno do concreto em que "tornou-se sempre mais difícil, paradoxalmente, o retorno para o concreto" (p. 19).

A estratégia de Flusser (1984) parece ser a de analisar o que há de mais material como forma de não se deslumbrar pelas imagens técnicas, para assim delinear seu imenso potencial de deslumbramento. As imagens técnicas possuem sua própria magia. Podem causar um certo estado de alucinação. Possuem complexas contradições em sua pós-historicidade, sua circularidade, sua bruxaria. "As imagens técnicas sugam toda a historicidade para suas superfícies e constituem uma eterna memória rotativa da sociedade" (p. 14)7 . De acordo com o autor, a invenção da imagem técnica altera o funcionamento do mundo como apenas a invenção da escrita alterou - a escrita, que nos retirou do mundo regido pelas imagens tradicionais, é substituída em sua importância pelas imagens técnicas. 0 papel de uma filosofia da fotografia seria o de mapear as possibilidades de liberdade em relação aos limites dos aparatos (GONÇALVES, 2013).

Quando Flusser menciona tais alterações no funcionamento do mundo, ele se refere essencialmente à mediação. Aqui, simplifico para fins de reflexão em duas formas: linguística e imagética. A primeira pode nos lembrar de seu representante mitológico, Hermes, inventor do alfabeto e deus-significador segundo Derrida (apud GALLOWAY, 2014). Hermes é o mensageiro viajante, esperto, criativo, fluido, mas também promíscuo e ambíguo. Ladrão. Seus aspectos ditos negativos são consequência direta do seu dom de circular, sua eloquência, as linhas que se formam

\footnotetext{
${ }^{7}$ Nessa e nas demais citações de originais em língua estrangeira, a tradução é minha.
} 
rapidamente e se cruzam e voltam e seguem em frente até desaparecer. 0 teórico em mídia e comunicação Alexander Galloway (2014) registra, no entanto, que Hermes não era o único mensageiro dos deuses.

Menos reconhecida e teorizada, havia Íris - aquela que, segundo Barthes (apud GALLOWAY, 2014, p. 45), não tem nada a dizer: "Ela repassa a mensagem, mas nada além disso. É simplesmente uma questão de estar presente para contar". Segundo Galloway (2014), Íris é a mensageira imanente e que exala proximidade, ao contrário de Hermes, a respeito de quem nunca se sabe com precisão onde está ou para onde vai. Íris apresenta em si mesma algumas certezas, ela possui concretude e não vem acompanhada de significados - para isso, seria necessário imaginação. Enquanto é prática, é também etérea; matematizável e poética. Hermes representa a hermenêutica, "a arte da interpretação textual compreendida como uma viagem entre textos" (p. 29), enquanto Íris, a deusa do arco-íris, representa iridescência. Se traçássemos um paralelo entre o que Galloway delineia e o que Flusser relaciona como escrita e imagem enquanto formas de mediação, Íris se aproximaria da ideia de imagem tradicional, já que sua materialidade se relaciona ao que Flusser considera como a mediação que exige menos gestos abstraidores, ou seja, menos passos para trás.

No entanto, ao elaborar essa relação, surge também a dúvida de se há espaço nessa mitologia das mediações descrita por Galloway para a imagem técnica. Estando Íris relacionada a visualidade, a tendência é parear a imagem técnica a ela, mas falta algo. Pode-se descobrir o quê pegando a dica de Flusser sobre a diferença entre os dois tipos de imagem: o nível de abstração. Segundo seu entendimento, imagem técnica é imagem criada pelo homem que foi transformada em texto e então em aparato e, depois, por um botão, em imagem técnica. Para Galloway (2014), iluminação e inspiração são temas de Íris, enquanto a cegueira e a opacidade são temas de Hermes. De acordo com Flusser, a opacidade já é própria das imagens tradicionais e é exacerbada na imagem técnica devido à superficialidade. Proponho que a imagem técnica possa significar, portanto, nessa reflexão, Íris a partir de Hermes: um salto que transforma Íris, atualizada e abstraída por Hermes, em imagem técnica, unindo 
iridescência e concretude a circulação, mistério e ilusão. Coincidentemente, a deusamensageira-imagética Íris é mulher e Hermes, um homem, e o salto anterior é o que considero melhor se aproximar do conceito de feminilidade.

Como Simone de Beauvoir (1953) elabora, há muito existe a ideia indisputável e absoluta da mulher enquanto ente místico e misterioso, ideia tal que as mulheres de carne e osso poderiam apenas aceitar, pois, caso seu comportamento contradiga o conceito, são elas as mulheres erradas: "Nos é dito que não é que a feminilidade seja uma falsa entidade, tais mulheres é que não são contempladas" (p. 260). A feminilidade e seus códigos têm sua centralidade na ideia do vazio, do nulo, que se expressa pela submissão e uma transcendência, distinta da masculina, que se dá por meio dessa experiência de sacrifício (DWORKIN, 1974).

As pernas fechadas, o ocupar pouco espaço, o falar baixo, o buscar ser sempre um espaço confortável para os outros. A feminilidade seria a constituição do vácuo ou, como disse a autora feminista Sheila Jeffreys (2005), a ritualização da submissão. "As mulheres não têm sexo, elas são um sexo a ser desfrutado. As mulheres são desprovidas do apêndice principal e seus atributos sociais, portanto, sua qualificação é nula" (NAVARRO-SWAIN, 2014, p. 40) ou "A mulher como paródia do humano" (p. 49). Como explica a filósofa Genevieve Lloyd (1984) em seu minucioso e extenso trabalho sobre o assunto, o feminino na filosofia ocidental é continuamente associado ao indeterminado (negativo). Dizer, entretanto, que o conceito de feminilidade se resume a isso é deixar de lado uma de suas maiores características, que é o aparentar (BROWNMILLER, 1984; WOLF, 2002): o aspecto decorativo, agradável, sedutor, encantador, bonito por fora - nunca por dentro, pois não há dentro. 0 dentro é um mistério. Na verdade, o que acontece é que a imagem está presente, mas, como o interior é colocado como vazio, oco, zero, caixa-preta, a imagem é lida como decoração.

No caso das imagens tradicionais, é fácil verificar que se trata de símbolos: há um agente humano (pintor, desenhista) que se coloca entre elas e seu significado. Este agente humano elabora símbolos "em sua cabeça", transfere-os para a mão munida de pincel, e de lá, para a superfície da imagem. (...) No caso das imagens técnicas, a situação é menos evidente (FLUSSER, 1984, p. 10). 
Os aspectos que Flusser atribui à imagem técnica, o fato de ser uma espécie de barragem, o feitiço que vem de sua circularidade, sua aparente objetividade ilusória, o fato de que parecem janelas mas são apenas superfícies, sua indecifrabilidade e, ao mesmo tempo, seu automatismo, todas essas sensibilidades podem ser estreitamente relacionadas ao conceito de feminilidade verificado historicamente pelas teorias feministas de primeira, segunda e terceira onda. 0 que essa relação entre estes dois conceitos, o de feminilidade e o de pensamento estético fotográfico, poderia possibilitar em termos de uma filosofia da fotografia? De que formas ambos podem se entrelaçar?

Como pontua Arlindo Machado (2010, p. 22), chama atenção em Flusser "sua posição divergente com relação tanto à posição tecnófila quanto à corrente tecnófoba", que é uma perspectiva que interessa mais aqui do que a de uma glorificação dos aparelhos enquanto meios revolucionários. Não interessa também julgar a imagem técnica enquanto boa ou má ou quais as formas preferíveis de mediação. Deve-se antes pensar nas formas de “'desprogramar' a técnica, distorcer as suas funções simbólicas, obrigando-as a funcionar fora de seus parâmetros conhecidos e a explicitar os seus mecanismos de controle e sedução" (MACHADO, p. 22) - como escapar, "hackear", subverter a caixa-preta para instaurar heterogeneidades e outras categorias, escapar de padronizações, ao mesmo tempo em que compreendemos nosso limitado poder de escolha diante do aparato utilizado corretamente, para evitar a programação do sensível.

Se é natural e até mesmo desejável que uma máquina de lavar roupas repita sempre e invariavelmente a mesma operação técnica, que é a de lavar roupas, não é todavia a mesma coisa que se espera de aparelhos destinados a intervir no imaginário, ou de máquinas semióticas cuja função básica é produzir bens simbólicos destinados (...) à sensibilidade (MACHADO, 2010, p. 49)

De forma paralela, o conceito de feminilidade também representa uma espécie de programação simbólica que poderia ser questionada em seu automatismo e constitui uma sensibilidade que tem valor de consumo, troca e circulação. Delinear essas relações para buscar caminhos em uma filosofia estético-política da fotografia -, pois "toda imagem contribui para que a mundivisão da sociedade se altere" 
(FLUSSER, 2008, p. 21) - é parte do desafio de localizar nesse encontro possibilidades de ação por meio do aparato e outras estruturas.

\section{Comum}

No lugar do encontro das dimensões estética e política das quais fala o filósofo Jacques Rancière (2009), há um foco voltado para a vida e para a experiência que pode nos auxiliar a pensar sobre o espaço 'comum' entre as pessoas. Nessa relação, vemos "atos estéticos como configurações da experiência, que ensejam novos modos do sentir e induzem novas formas de subjetividade política" (p. 11). Nessa elaboração, Rancière menciona a situação do artesão que não pode participar de outras atividades devido a seu trabalho e se refere à partilha do sensível como o que "faz ver quem pode tomar parte no comum em função daquilo que faz, do tempo e do espaço em que essa atividade se exerce" (2009, p.16). Diante dessa divisão entre os que possuem competência para o trabalho e os que a possuem para criação, pensamento e decisão, podem ser questionadas as possibilidades de participação efetiva do artesão no "espaço entre" que define o comum - uma análise que faz pensar no clássico ensaio de Virginia Woolf (1929) Um teto todo seu, em que ela aborda a questão do quanto a realidade material da mulher é definidora de sua emancipação e liberdade como autora. Rancière avança ao afirmar que as questões da forma têm parte com certa "politicidade" do sensível relacionada a participação e privilégios. Segundo seu argumento,

\footnotetext{
As artes nunca emprestam às manobras de dominação ou de emancipação mais do que lhes podem emprestar, ou seja, muito simplesmente, o que têm em comum com elas: posições e movimentos dos corpos, funções da palavra, repartições do visível e do invisível (RANCIÈRE, 2009, p. 26).
}

O que ele chama aqui de arte é uma maneira de pensamento e experiência estética, um estado de experimentação da forma. A partilha democrática do sensível, portanto, implica um mundo 'comum', em que as maneiras de ser são distribuídas, compartilhadas, ocupadas na experiência. 
Ao lado dessa discussão, coloco a utilização, pela filósofa Janice Raymond (1986), do conceito de worldlessness, de Hannah Arendt (1958), para falar sobre uma espécie de alienação do mundo vivenciada pelas pessoas que se encaixavam na categoria histórico-social mulher na sociedade ocidental. Segundo Raymond, como as mulheres tiveram historicamente muito pouco controle sobre as leis às quais estiveram submetidas e muito pouco poder político no mundo, e como as estruturas do mundo foram construídas por homens, muitas teriam desenvolvido uma espécie de dissociação da realidade. A falta de conexão e identificação com o "mundo real", o mundo da vita activa, sendo este o espaço público, as tornaria pouco interessadas nas estruturas que causam sua própria situação, tornando-as, portanto, menos dispostas a modificá-la ativamente. Diante dessa sensação de distanciamento da realidade social e do sentimento de incapacidade de causar qualquer intervenção ou interrupção nessa dinâmica, as mulheres se voltariam para si mesmas e para sua própria subjetividade como uma forma de defesa e, também a partir dessa reação, seria confirmada a ideia de que mulheres seriam seres introvertidos, misteriosos e poéticos.

"Em um mundo que vê mulheres como algo supérfluo, ou seja, desnecessário, marginal, desimportante e dispensável", a dissociação pode ter um efeito catastrófico, pois soma-se às amarras estruturais de forma a remover as mulheres de "uma participação compartilhada do que deveria ser um mundo comum, isto é, um mundo que é organizado por todos que o habitam" (RAYMOND, 1986, p. 154, grifo meu). Dessa situação se estabeleceria para parte das mulheres ocidentais uma solidão e contemplação decorrentes dessa não participação no mundo, a palavra mundo sendo compreendida também como o que está entre as pessoas; o espaço que simultaneamente separa e relaciona os indivíduos (ARENDT, 1958, p. 52-53), como bem ilustram os vizinhos das irmãs Lisbon, do filme As virgens suicidas, de Sofia Coppola, presas em casa por ação de seus pais protetores e conservadores e buscando refúgio em revistas de viagem, sobre as ficções do feminino:

E então começamos a aprender sobre as vidas delas, passando a colecionar memórias de momentos que não vivemos. Sentíamos o aprisionamento de ser uma garota, a forma como isso deixava sua mente 
ativa e sonhadora e como você acabava sabendo quais cores iam bem juntas. $^{8}$

Pode-se dizer que há algumas décadas uma parcela das mulheres ocidentais já possui certa participação no comum. Essa sensibilidade que descrevo, no entanto, ainda é bastante reconhecível. Ao construir um trabalho e a si mesma enquanto artista, ao localizar-se na política e partilhar essa sensibilidade, abrem-se possibilidades. Em entrevista, a artista americana Audrey Wollen toca no assunto e propõe alternativas nesse sentido a partir da herança da experiência de outras mulheres - a aparente passividade com que historicamente elas vivenciaram violências físicas e simbólicas deveria ser compreendida, ela propõe, como uma forma de resistência às estruturas opressivas:

Sofrimento, fome, inanição e eventualmente suicídio foram postos de lado como sintomas de doenças mentais e até mesmo puro narcisismo de garotas. Estou propondo que isso é, na verdade, ativo, autônomo e político, além de devastador. ${ }^{9}$

O que a artista descreve lembra a noção de patologias de protesto como proposta pela teórica cultural Susan Bordo (2003, p. 174), na qual Bordo diz que em certas doenças tipicamente femininas como histeria, agorafobia ou anorexia, "o corpo de mulheres pode ser visto como uma superfície no qual construções convencionais de feminilidade são expostas de maneira gritante para contemplação". Bordo fala sobre a prática da feminilidade sendo exercitada e levada ao seu extremo enquanto um tipo de revolta e busca por solução para as limitações impostas. Ou seja, as próprias condições de mulheres ao serem levadas de maneira ultraliteral produziriam uma implosão desse controle - não obstante, também contraproducente, como a mudez das histéricas ou a debilitação das anoréxicas. Wollen acrescenta a sugestão de que a noção de protesto que conhecemos carregaria em si signos históricos do

\footnotetext{
${ }^{8}$ Roteiro de As virgens suicidas (1999), de Sofia Coppola, disponível em: <http://www.script-orama.com/movie_scripts/v/virgin-suicides-script-transcript.html>; acessado em 29/08/2017. 9 Trecho da fala de Audrey Wollen no artigo Audrey Wollen on Sad Girl Theory no site Cultist Zine, disponível em: <http://www.cultistzine.com/2014/06/19/cult-talk-audrey-wollen-on-sad-girltheory/>; acessado em 14/06/2017.
} 
masculino: violência, armas, espaço público - tudo que a isso escapa é considerado despolitizado.

Em diversos pontos do globo, como na galeria Arcadia Missa em Londres, surgem propostas semelhantes sobre a relação entre políticas feministas e um olhar sobre feminilidades, esses dois elementos não como inimigos, mas como formadores de um paradoxo cuja complexidade não deve ser menosprezada. No texto de abertura da exposição Dry Wipe, a curadora Rósza Zita Farkas ${ }^{10}$ cita a compreensão da teórica cultural Nelly Richard sobre as diferenças entre 'estética feminina' e 'estética feminista'. A primeira, segundo Richard, normalmente conotaria arte que expressa a mulher enquanto fato natural, essencial, e não "uma categoria simbólicodiscursiva formada e deformada pelos sistemas de representação cultural", enquanto a segunda seria politicamente consciente. Zita Farkas afirma, em consonância com o que argumentamos aqui, que ambas podem existir simultaneamente.

Para compreender as formas em que isso se dá, é necessário olhar para as complexidades dessas relações. É preciso, também, avançar na configuração de um conceito político de feminilidade que extravase a elaboração de um diagnóstico da dinâmica patriarcal. Um termo de utilidade é feminilidade hegemônica, utilizado pelas teóricas sociais Karen D. Pyke e Denise L. Johnson (2003) no sentido de assinalar comportamentos e expectativas contemporâneas sobre mulheres. Embora exista uma aproximação, o sentido no qual o utilizo aqui é diferente. Penso feminilidade hegemônica no sentido de ficções e associações simbólicas instituídas em relação a feminilidade ao longo da história ocidental - muito registradas em um procedimento comum do feminismo de segunda onda, no qual se realizava uma leitura crítica das mais diversas e célebres obras escritas por homens. 0 termo feminilidade hegemônica é especialmente útil aqui enquanto lembrança de seu caráter também ocidental e colonialista.

10 Texto disponível em:

<http://www.sleepingupright.com/homepage/Exhibitions/Dry\%20Wipe/Handout.pdf>, acessado em 20/08/2018. 
Como apontado ao longo do desenvolvimento da teoria feminista, os imaginários que acompanham a feminilidade hegemônica nunca se aderem completamente aos corpos de mulheres. 0 que, no entanto, não recebeu atenção suficiente foi o fato de que, pela proximidade que essa feminilidade hegemônica conceitual tem com parâmetros que orbitaram historicamente ao redor de sujeitos brancos, como a fragilidade e inocência (FRANKENBERG, 1997; DIANGELO, 2011), adere menos ainda aos corpos que não são brancos. Pela sintomática falta de estudos que se voltem precisamente para as incorporações e mutações da feminilidade ocidental em diferentes contextos contemporâneos, eu me apoio no trabalho das teóricas sociais, culturais e feministas que cito para fazer uma proposição que será adotada durante o curso desse texto.

Se o caminho para mulheres brancas serem consideradas seres misteriosos e poéticos foi um caminho de apropriação de seus corpos com a justificativa da afetividade e a criação de um regime de trabalho reprodutivo não remunerado (FEDERICI, 2017), acompanhado do ideal da família tradicional (COLLINS, 2000), os caminhos que estabeleceram o mistério por trás da simbologia da superfície epidérmica negra de mulheres trazem consigo uma história de violência muito mais explícita, da criação de um regime de trabalho não só reprodutivo como produtivo, gerando contornos distintos entre as duas experiências. Essa trajetória deposita um peso na qualidade material do corpo negro feminino, produzindo imagens controladoras que a teórica social Patricia Hill Collins (2000) elenca, que incluem temas de exagerada sexualização e agressividade, enquanto para mulheres asiáticas, por exemplo, as imagens controladoras seriam de exagerada submissão (PYKE E JOHNSON, 2003).

A aderência da feminilidade hegemônica à experiência varia de maneira específica implicada na intersecção não só racial, mas também de classe, sexualidade e outros. No entanto, na cultura ocidental, a tendência é que experiências de feminilidades continuem mediadas pelo que defini como feminilidade hegemônica. Nesse jogo de aproximações entre a experiência possível e ideal aspiracional padronizado, podese aludir a um fenômeno: a menor distância possível entre os dois continua infinita, 
como ímãs sendo forçados juntos nos lados em que se repelem, num movimento contínuo, instável e errático. No espaço intermediário onde operam essas forças, uma alquimia acontece - não apenas uma questão de grau, que regraria mais ou menos feminilidade, mas uma questão de substância.

É necessário entender, então, essa feminilidade hegemônica enquanto uma categoria fantasmagórica, que recai sobre os corpos e que se transforma na relação entre os dois, mas que jamais pode encontrar e encaixar perfeitamente em corpo algum - é, de fato, inatingível. Partindo disso, o que nomeio aqui enquanto conceito político de feminilidade é a noção vivida dessa microdinâmica de aproximação e distanciamento, de aspiração e recusa da categoria; consciência, experimentação e instrumentalização da maneira como a feminilidade funciona; reação aos seus efeitos e constituição de si, ou seja, movimentação de poder e estratégia de sobrevivência. Essas feminilidades políticas seriam o ponto vago de contato.

A concepção de uma performance paródica de gênero como desestabilizador e significador político pode ser traçada até os desenvolvimentos da filósofa Judith Butler em seu trabalho Problemas de gênero: Feminismo e subversão da identidade (2011). Enquanto essa proposição de performatividade é relevante aos desenvolvimentos feitos aqui, é importante questionar nesse trabalho de Butler o pessimismo com que a autora aborda lutas sociais por mudanças materiais através e para além dessa desestabilização, como aponta a filósofa Martha Nussbaum em suas críticas (2003). Outra ressalva em Butler (2011) é o fato de serem tomados como elementos principais o binarismo e a heteronormatividade, não sendo focada a ótica de hierarquias estruturais. Nesse sentido, apesar de não me alongar nessa questão, sugiro que acompanhemos a proposta da socióloga brasileira Heleieth Saffioti (2004), de procurar pensar o conceito de gênero sempre atrelado ao de patriarcado.

Com um foco no binário e nas identidades fixas, a proposta original de Butler tende a focalizar a subversão que acontece em corpos estranhos e os desenvolvimentos que seguiram de seu trabalho foram, em sua maioria, nesse sentido dos desvios mais aparentes. 0 que me interessa nessa pesquisa enquanto gesto artístico, no entanto, 
é enxergar o gênero quando mais próximo do "adequadamente" performado, para então desnaturalizá-lo, politizá-lo em sua aparente adequação e problematizar o fato de que não pode existir pureza e perfeição na mimese desses estados. Encontrar os protestos que circulam nas superfícies e que podem passar como imperceptíveis. Em outras palavras, seria como navegar ao redor de questões de conformidade e aderência da feminilidade hegemônica para denunciar que, como tais, nunca podem se consumar.

Desejo uma compreensão da superfície enquanto conteúdo, superfície-epiderme, espaço de divergência de forças, fino e frágil local de possível tato, contato e protesto. Essa tática talvez entre em choque com o caminho que Janice Raymond (1986) teria inferido - que seria de rejeitar o que corre o risco de ser contraproducente nas feminilidades - mas vejo como um ato estético-político e um espaço propício a afirmação de suas implicações. De certo, essa performatividade crítica das feminilidades é também um risco, um local dúbio para se estar entre o hegemônico e o contra-hegemônico. Intuo, no entanto, que a inclinação para tais questões poderia somar a esse desanexo do sistema de ideias que propõe a feminilidade como consequência essencialista de algo, seja esse algo biológico ou metafísico.

Para tratar das possibilidades poéticas que residem aí, o olhar se voltaria para as possíveis formas de existência dessa paródia, exercício, experimentação, autoetnografia e autoapropriação, sem amarras sobre o que seria um formato político ideal estável, pois a forma, a experiência estética, não precede uma razão estática, homogênea, simplificada. Tal perspectiva se alinha a fala do teórico cultural Stuart Hall (2013, p. 286) quando este diz que: "quase todo inventário fixo nos enganará. 0 romance é uma 'forma' burguesa? A resposta só pode ser historicamente provisória: quando? Quais romances? Para quem? Sob quais condições?". 


\section{Sem penetração}

Olhar para o meu próprio processo e para os processos das artistas ao meu redor a partir do pressuposto da superfície enquanto conteúdo traz questões sobre a ideia do autor, que historicamente vem imbuído de uma ideia de profundidade, transposição, atravessamento do sujeito - seja ele o sujeito iluminista, moderno ou pós-moderno. Quero apontar aqui alguns dos paradoxos entre ideias de autoria e feminilidade. Começo citando o trabalho Truisms (1980), de Jenny Holzer, que colocou em jogo questões de autoria e foi profético de um certo tipo de linguagem que se tornaria extremamente popular com a introdução da Internet na vida cotidiana depois dos anos 1990. Nessa obra, Holzer utiliza a linguagem a partir de frases vernaculares que para alguns denotam conflito ideológico, pelo fato de não serem coerentes em si/entre si, e para outros denotam simplesmente o vazio inerente à linguagem que passa a depender do contexto e das relações de poderes para significar. Em entrevista de 1986, quando perguntada sobre ser ouvida enquanto mulher, Holzer responde que sempre tenta manter sua voz não identificável e que não gostaria de ser considerada uma voz feminina, pois prefere que não exista nenhuma associação particular em relação à voz justamente para que possa ser percebida como verdadeira. Em seguida, entretanto, na mesma entrevista, como apontado por Gordon Hughes (2006, p. 438), ela declara: “mas, sim, eu desejo que minha voz seja ouvida e, sim, é a voz de uma mulher".

Gosto de pensar essa fala de Holzer como sugestiva do paradoxo da identidade e da autoria feminina. Não defendo que o problema aqui delineado seja meramente identitário - no sentido de que não é a identificação do sujeito a causa principal do nó - mas, sim, que o cerne esteja na imbricação da estética e da política pela experiência. Existe, no entanto, uma relação nesse lugar: se essa imbricação tem a ver também com o poder de participação ativa e o modo como são concebidos os sujeitos em sua participação, é consequência falar em noções de identidade e na autoridade de se posicionar.

O teórico cultural Stuart Hall (2006) esboça uma trajetória do processo de deslocamento do sujeito, desse "sentido de si", estável e indivisível, e da 
consequente "narrativa do eu" que parte do humanismo renascentista do século XVI e é reforçado pelo iluminismo do século XVIII. Precursor da filosofia moderna, Descartes (apud HALL, 2006, p. 27) tem parte nesse processo ao colocar "no centro da 'mente' (...) o sujeito individual, constituído por sua capacidade para raciocinar e pensar". A filósofa Genevieve Lloyd (1984, p. 2) argumenta que ao longo da história da filosofia a razão foi continuamente associada aos homens e a tudo que de forma simbólica remetesse ao masculino - e descreve uma dinâmica que poderia representar as abstrações da penetração enquanto símbolo de constituição do sujeito: “o conhecimento racional era construído através da transcendência, transformação ou controle de tudo que era considerado natural, enquanto o feminino era justamente o que o conhecimento racional transcendia, dominava ou simplesmente deixava para trás".

É um problema que pode ser traçado até as próprias discussões sobre autoria a partir da leitura de N. Katherine Hayles do extenso trabalho de Mark Rose sobre o assunto. Rose (apud HAYLES, 2005) demonstra que o debate sobre propriedade intelectual consolidou ideias importantes sobre criatividade e autoria. Na época, a discussão se dava ao redor da literatura, e foi estabelecido legalmente que a autoria era composta por questões de estilo e espírito - a forma da obra seria apenas reflexo desses elementos -, concepção que ajudaria a maximizar o capital cultural dos produtos. Sobre isso, Hayles argumenta que é enfatizada a hierarquia de valores a partir do espírito criativo: o autor que trabalha pela glória, e o que escreve por necessidade ou dinheiro.

Se às mulheres não seria permitido o mesmo tipo de transcendência intelectual, mas apenas uma versão própria de "transcendência feminina" que ocorre pelo sacrifício, como se estabelece conceitualmente uma autoria feminina? 0 impasse remete a um problema que Joan Scott (2005, p. 17) assim revela:

Os homens eram indivíduos porque eram capazes de transcender o sexo; as mulheres não poderiam deixar de ser mulheres e, assim, nunca poderiam alcançar o status de indivíduo. (...) Todas as mulheres caem na mesma categoria, ao passo que cada homem é um indivíduo em si mesmo; a fisionomia das primeiras se conforma a um padrão geral; a dos últimos é ímpar para cada caso. 
Ao descrever o processo de descentração do sujeito, Stuart Hall (2006) sintetiza alguns atores principais, que seriam a psicanálise, o pós-estruturalismo, a virada linguística e o feminismo. Esses agentes contribuíram para o desenvolvimento de uma noção do sujeito composta por identidades fragmentadas. Hall demonstra o problema ao descrever a situação de um juiz negro que seria indicado por um político conservador para um cargo e, concomitantemente, acusado de assédio sexual por uma mulher negra de posição hierárquica inferior à dele, e apontar como essa profusão de identidades (raça, gênero, classe social, posicionamento político) em jogo afetaria as visões e posições diante do caso.

Autora feminista chave na teoria crítica racial e desenvolvedora do conceito de interseccionalidade, Kimberlé Crenshaw (1994) propõe que as identidades específicas sejam vistas como estruturais e interconectadas, uma decorrência das condições que vulnerabilizam certas experiências e criam, a partir dessas experiências, categorias. Crenshaw critica a parcela das políticas identitárias contemporâneas que, ao totalizar múltiplas identidades, cai em hibridismo pacificador e acaba despolitizando as questões estruturais que produzem tais identidades em conjunto. Nesse ponto, seu pensamento se aproxima do que o sociólogo Ramon Grosfoguel (2007) afirma quando observa que existiu por muito tempo na história ocidental uma política identitária do homem branco e que o que acontece agora não é novo, mas apenas a apropriação dessa estratégia pelas lutas minoritárias - e aí reside a questão de avaliar se essa seria uma estratégia interessante. Os mecanismos das políticas identitárias às vezes parecem reforçar a importância do indivíduo num sentido que pode escorregar para o multiculturalismo que eufemiza as diferenças e tensões numa cooptação neoliberal.

Atentos a essa armadilha, ainda é possível dizer que, para os que foram excluídos historicamente da possibilidade de afirmar uma identidade e agência, a descentração do sujeito que oferece identidades fixas e fragmentadas aparenta ser uma oportunidade interessante de encontrar uma definição de individualidade que lhes sirva. Em outra chave da descentração, seria apresentada uma configuração menos absoluta e fixa, com noções mais fluidas. Existem, ainda assim, possíveis 
problemas que devem ser sublinhados quando esses desenvolvimentos ainda demonstram uma epistemologia calcada no sujeito enquanto ser masculino.

Como a filósofa e teórica feminista Rosi Braidotti (2002, p. 15) aponta, autoras feministas, negras e pós-coloniais destacaram o paradoxo de que são os "pensadores localizados no centro dos impérios passados e presentes que estão ativamente desconstruindo o poder do centro" e gerando a proliferação de noções de alteridade quando, no entanto, esses que são considerados outros não estão exatamente objetivando um livrar-se de identidades, mas sim questionando: "como podemos nos desfazer de uma subjetividade que nós ainda não estivemos, historicamente, sequer autorizados a possuir?".

Um exemplo de tensões diz respeito a relação entre teoria feminista e Deleuze, como a própria Braidotti, em seu trabalho voltado para os desenvolvimentos deleuzianos, argumenta. Braidotti descreve que quando Deleuze fala de devires minoritários, para os quais o devir mulher é parte chave do processo, ele busca escapar de uma noção falocêntrica ao não se engajar com a suposição de uma falta (e sim com uma imanência radical). No entanto, Braidotti aponta que Deleuze, ao assumir a mulher enquanto outro no sistema, acaba a definindo também por negação. Além disso, dilui a diferença em "múltiplos e indiferenciados devires" (p. 77) e ignora em seu desenvolvimento qualquer assimetria entre os sexos, inclusive afirmando que "a ênfase no feminino é restritiva” (p. 81) e criticando feminismos que se recusam a dissolver o sujeito 'mulher' para desaguar em um devir generalizado. Essa posição é criticada por teóricas feministas, como a própria Braidotti e a teórica cultural e estudiosa de Deleuze Claire Colebrook (apud BRAIDOTTI, 2002).

O que exatamente Deleuze e Guattari pretendem quando retiram de Woolf e do movimento das mulheres os conceitos de identidade, reconhecimento, emancipação e sujeito para partir para um novo plano de devir? (COLEBROOK apud BRAIDOTTI, 2002, p. 81).

Nos meandros da dissolução do sujeito, diferenças correm o risco de serem desconsideradas, levando a uma implícita armadilha de universalidade. Em uma consideração anterior e que pode figurar enquanto exemplo do que Braidotti apontou, a teórica e cineasta Trinh T. Minh-ha (1989) sugere que a estratégia que 
ela descreve da filósofa Julia Kristeva de se engajar em uma prática negativa como espaço das mulheres nessa desconstrução, de rejeitar tudo que é estruturado e significativo, não seja uma decisão acertada. Minh-ha argumenta que, embora venham de um lugar que busca questionar identidades, essas iniciativas tendem a privilegiar a ideia de "mulher" enquanto atitude e desprivilegiar "mulher" enquanto existência.

Como posso perder, manter ou ganhar uma identidade (feminina/masculina) quando é impossível para mim tomar uma posição estando fora dessa identidade de onde eu presumidamente a alcanço e a apalpo? (...) Declarar provocativamente, como Kristeva faz, que se deveriam dissolver 'inclusive identidades sexuais' é, de alguma forma, negligenciar a importância da virada pela qual a noção de identidade passou nos discursos das mulheres (MINH-HA, 1989, p. 95-105).

A já citada Kimberlé Crenshaw (1994) compartilha desse incômodo: ela descreve uma das práticas não essencialistas calcadas em correntes pós-modernas de que "ideias consideradas naturais ou representacionais são na verdade socialmente construídas em uma economia linguística da diferença" como problemática quando se sugere que, por serem categorias socialmente construídas, "não haveria, por exemplo, 'negros' ou 'mulheres', e por consequência não faria sentido reproduzir essas categorias ao se organizar ao redor delas" (p. 106). Ela prossegue em fala que se aproxima à de Trinh T. Minh-ha:

Isso não é negar que o processo de categorização é em si um exercício de poder, mas a história é muito mais complicada e cheia de nuances (...) o processo de categorização - ou, em termos de identidade, nomeação - não é unilateral (CRENSHAW, 1994, p. 106).

Aqui se colocam duas questões. A primeira: como se posicionar entre (1) uma dissolução do sujeito que seja uma espécie de cavalo de Troia para a emancipação política e (2) uma supervalorização do indivíduo totalizante? E a segunda: no caso das mulheres - que foram simbolicamente retiradas dos conceitos de subjetividade durante a história da filosofia, desconsideradas como sujeitos até muito recentemente, e que encontram ainda seus próprios nós nas teorias modernas e pósmodernas que deslocam os conceitos de indivíduo - como encontrar um conceito de autoria que faça sentido dentro da paisagem contemporânea? Porque "mulher" parece continuamente recair na armadilha do fragmentado, do negativo, do não 
homem, do metafísico, do vazio. As identidades fragmentadas e/ou diluídas, que se tornam novidade para o sujeito masculino, talvez não sejam assim tão novas para as mulheres. Um sujeito uno, porém, também não interessa, especialmente pensando a partir do conceito de interseccionalidade e de diferenças estruturais. Ao mesmo tempo, nomear o problema é importante - falar a respeito de mulheres, de gênero quando atrelado ao patriarcado, é fundamental. Volto à declaração de Jenny Holzer: mas quero que minha voz seja ouvida e, sim, é a voz de uma mulher. Ou ao poema que Trinh. T. Minh-ha cita ao tratar dessa questão:

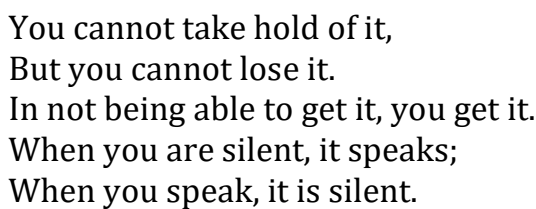

(CHENG-TAO-KE, apud MINH-HA, 1989, p. 121)11

O processo de busca e construção de uma epistemologia que atenda aos sujeitos da alteridade é recente, e o problema da identidade/autoria permanece, mas é mais útil quando reconhecido e delineado.

Ao reconhecer esses vazios e conformidades aparentes - aparecimentos e desaparecimentos diante de um olhar dominante que se constituiu através do que impossibilitou uma constituição feminina que fosse passível de ser reconhecida -, seria possível retomar a ideia de pontos cegos para apropriar-se dela de outra maneira? A hipótese que admito aqui é como possibilidade estratégica um "hackear" que, diferente do que inicialmente elaborava Vilém Flusser, não se dá por dentro, pela introdução, não se dá como um ato iconoclasta que visaria destituir a imagem de seu potencial feiticeiro. 0 "hackear" de que falo se aproximaria do que Flusser desenvolveu em seus trabalhos tardios, e consistiria em admitir a artificialidade da imagem como seu próprio valor e tencionar circular em tal complexidade (GULDIN, 2007). Transpondo para a relação da imagem técnica com a feminilidade: circular em sua própria opacidade, no que existe de específico e que a torna imperceptível, repetitiva, falsa, forçar a aparente homogeneidade como maneira de experimentar

\footnotetext{
11 "Você não a pode tomar, Mas não a pode perder. Ao não conseguir obtê-la, você a obtém. Quando você está em silêncio, ela fala; Quando você fala, é silenciosa."
} 
e explicitar os próprios mecanismos que tornam o encontro entre os olhares temporariamente inalcançável.

\section{REFERÊNCIAS BIBLIOGRÁFICAS}

ANJOS, Moacir dos. Local/global: arte em trânsito. Rio de Janeiro: Jorge Zahar, 2005.

ARENDT, Hannah. The Human condition. Chicago: University of Chicago Press, 1958.

BEAUVOIR, Simone de. The second sex. London: Lowe and Brydone. 1953.

BERGER, John. Ways of seeing. London: British Broadcasting Corporation and Penguin Books. 1972.

BRAIDOTTI, Rosi. Metamorphoses: towards a materialist theory of becoming. Cambridge: Polity Press. 2002.

BROWNMILLER, Susan. Femininity. New York: Linden Press/Simon \& Schuster, 1984.

BUSIA, Abena P. A. Performance, transcription and the languages of the self: interrogating identity as a "post-colonial" poet. In: JAMES, Stanlie M.; BUSIA, Apena P. A. (Ed.). Theorizing black feminisms: the visionary pragmatism of black woman. London: Routledge. 1993. p. 205-216.

BUTLER, Judith. Gender trouble: feminism and the subversion of identity. New York: Routledge. 2011.

COLLINS, Patricia Hill. Black feminist thought: knowledge, consciousness, and the politics of empowerment. 2. ed. New York e London: Routledge, 2000.

CRENSHAW, Kimberlé. Mapping the margins: intersectionality, identity politics, and violence against women of color. In: FINEMAN, Martha Albertson; MYKITIUK, Rixanne. (Ed.). The Public nature of private violence. New York: Routledge. 1994. p. 93-118.

DWORKIN, Andrea. Pornography: men possessing women. New York: Penguin Books. 1979.

DWORKIN, Andrea. Woman hating. New York: Penguin Books, 1974.

FEDERICI, Silvia. O feminismo e as políticas do comum. São Paulo: n-1 edições, 2017. 
FRANKENBERG, Ruth. Local Whitenesses, Localizing Whiteness. In: (Ed.).

Displacing whiteness: essays in social and cultural criticism. Durham: Duke University Press, 1997. p. 1-33.

FLUSSER, Vilém. $O$ universo das imagens técnicas: elogio da superficialidade. São Paulo: Annablume. 2008.

FLUSSER, Vilém. Towards a philosophy of photography. Gottinger: European Photography, 1984.

GALLOWAY, Alexander R. Love of the middle. In: GALLOWAY, Alexander R.; THACKER, Eugene; WARK, McKenzie. Excommunication: three inquiries in media and mediation. Chicago: The University of Chicago Press, 2014.

GONÇALVES, Osmar. Estética da fotografia: um diálogo entre Benjamin e Flusser. Flusser Studies, 15. 2013.

GULDIN, Rainer. Iconoclasm and beyond: Vilém Flusser's concept of technoimagination. Studies in Communication Sciences, Lugano, v. 7, n. 2, p. 63-83, 2007.

GROSFOGUEL, Ramón. Dilemas dos estudos étnicos norte-americanos: multiculturalismo identitário, colonização disciplinar e epistemologias descoloniais. Ciência e Cultura, São Paulo, v. 29, n. 2, p. 32-35, 2007.

HALL, Stuart. Cultura popular e identidade. In: STUART, Hall; SOVIK, Liv. (Org.). Da diáspora: identidades e mediações culturais. Belo Horizonte: UFMG, 2013. p. 273291.

HALL, Stuart. A identidade cultural na pós-modernidade. Rio de Janeiro: DP\&A, 2006.

HUGHES, Gordon. Power's script or Jenny Holzer's art after 'Art after philosophy'. Oxford Art Journal, v. 29 n. 3, p. 419-440, 2006.

JEFFREYS, Sheila. Beauty and misogyny: harmful cultural practices in the West. New York: Routledge. 2005.

KRAUS, Chris. Private parts, public women. The Nation Magazine, 16, novembro, 1998.

KRAUS, Chris. I love Dick. New York: Semiotext(e). 1997.

LLOYD, Genevieve. The Man of Reason: "male" and "female" in Western philosophy. Minneapolis: University of Minnesota Press. 1984.

MAHARAJ, Sarat. Perfidious fidelity: the untranslatability of the other. In: MAHARAJ, Sarat; HALL, Stuart. Modernity and difference. London: Institute of International Visual Arts. (Annotations, 6). 2001. p. 26-34. 
MINH-HA, Trinh T. Woman, native, other: writing postcoloniality and feminism. Bloomington: Indiana University Press. 1989.

NAVARRO-SWAIN, Tania. Por falar em liberdade. In: STEVENS, Cristina; OLIVEIRA, Susane Rodrigues de; ZANELLO, Valeska. (Org.). Estudos feministas e de gênero: articulações e perspectivas. Ilha de Santa Catarina: Mulheres. 2014. p. 36-51.

NUSSBAUM, Martha. The professor of parody. Raisons politiques, n. 4, p. 124-147, 2003.

PLANT, Sadie. Feminisations: Reflections on women and virtual reality. In: JONES, Amelia (Ed.). The Feminist and Visual Culture Reader. 2. ed. New York: Routledge, 2010. p. 640-641.

PYKE, Karen D.; JOHNSON, Denise L. Asian American women and racialized femininities: "Doing" gender across cultural worlds. Gender \& Society, Oakland, v. 17, n. 1, p. 33-53, fev. 2003.

PLANT, Sadie. Feminisations: Reflections on women and virtual reality. In: JONES, Amelia (Ed.). The Feminist and Visual Culture Reader. 2. ed. New York: Routledge, 2010. p. 640-641.

PYKE, Karen D.; JOHNSON, Denise L. Asian American women and racialized femininities: "Doing" gender across cultural worlds. Gender \& Society, Oakland, v. 17, n. 1, p. 33-53, fev. 2003.

SCOTT, Joan. O enigma da igualdade. Revista Estudos Feministas, Florianópolis, v. 13, n. 1, jan.-abr. 2005.

WOLF, Naomi. The Beauty myth: how images of beauty are used against women. New York: HarperCollins, 2002.

WOOLF, Virginia. Um teto todo seu. São Paulo: Tordesilhas. 2014. Rio de Janeiro: Nova Fronteira, 2005.

Recebido em: 16/11/2018

Aprovado em: 16/11/2018 